\title{
Mentoring Support for Juveniles During and After Incarceration
}

\author{
Theresa A. Ochoa, School of Education, Indiana University-Bloomington \\ Sarah D. Swank, Statewide Juvenile Mentoring Director, \\ Indiana Department of Correction
}

\begin{abstract}
The HOPE (Helping Offenders Prosper through Employment) Mentoring Program is a university-based program that partners undergraduate mentors with incarcerated juveniles during their time spent in the facility and continues mentorship upon reentry to the community. We describe the principles of the mentoring program and highlight how the HOPE Mentoring Program has been implemented in the state of Indiana with juveniles with and without disabilities.
\end{abstract}

Placement in residential correctional confinement is a common response to juvenile delinquency. A 2014 report released by the U.S. Departments of Education and Justice indicated that approximately 60,000 juveniles were incarcerated in a correctional facility on any given day of the year. If correctional confinement is intended to change juveniles' behavior and help them grow into law-abiding adults (Suitts, Dunn, \& Sabree, 2014), community reentry support is needed since approximately $55 \%$ of juveniles who are released from confinement return to incarceration within one year of release (Davis et al., 2014). Clark and Unruh (2010) found that juveniles who exited confinement with support experienced more success when they returned to their communities compared with juveniles who received no such support. However, comprehensive reentry programming when a juvenile leaves residential confinement in Indiana, specifically, and the country, in general, is virtually nonexistent (Baltodano, Platt, \& Roberts, 2005; Clark, Mathur, \& Helding, 2011; Stephens $\&$ Arnette, 2000). Mentoring is one such support proven to result in positive social outcomes, including the reduction of recidivism (Jekielek, Moore, \& Hair, 2002). In this article, we describe the process of education and rehabilitation that exists in juvenile correctional facilities in the state of Indiana, underscore the personnel and policy challenges experienced in juvenile correctional facilities related to community reentry, and discuss the Helping Offenders Prosper through Employment (HOPE) Mentoring Program which connects undergraduate mentors to incarcerated juveniles during incarceration and upon community reentry.

\section{Juvenile Incarceration Process in the State of Indiana}

The United States has approximately 2,500 juvenile residential correctional facilities. All correctional facilities are required to educate juveniles under their care and provide reentry support when they return to their communities (Sheldon-Sherman, 2010; U.S. Departments of Education and Justice, 2014). However, there is no uniformity in how juvenile correctional facilities implement these two related responsibilities for juveniles under their custody since education and rehabilitative services are determined by each state (Suitts et al., 2014). In the state of Indiana, the Department of Correction is responsible for the custody, care, and education of all juveniles placed in a state residential facility 
(Suitts et al., 2014). There are three residential correctional facilities in the state of Indiana two for males and one for females. Although the total length of a sentence for some juveniles is determined by the juvenile courts, the exact release date of most juveniles is determined by a team who advises the superintendent who oversees all aspects of rehabilitation and education in each of the juvenile facilities. The release date of each juvenile can be shortened or extended, depending on how well behavioral or treatment expectations set by the team are met. The incarceration process in the state of Indiana includes three phases: (1) Intake, (2) Rehabilitation and Education, and (3) Transition. Each phase is described below.

The Intake phase of incarceration takes approximately two weeks. At intake, each juvenile is assessed to determine his or her medical and mental health condition, educational status, and vocational interests and needs. The intake process culminates in the establishment of a juvenile-specific rehabilitation and education program called the Individualized Learning Plan (ILP), which guides treatment throughout the duration of incarceration. Juveniles with disabilities have an additional Individualized Education Program (IEP) required by the Individuals with Disabilities Education Act (IDEA), the federal special education law that imposes additional service expectations for juvenile correctional facilities to provide for students with identified special education diagnoses (Ochoa, 2016).

The Rehabilitation and Education phase of incarceration is guided by the ILP and the IEP. Indiana's juvenile correctional facilities identify four levels of skill acquisition in the Rehabilitation and Education phase: (1) acknowledgement, (2) understanding, (3) application, and (4) demonstration. In the first level, the juvenile works to develop the skill to acknowledge the behavior he or she engaged in that resulted in incarceration. In the second level, the youth develops the skill to understand and gain insight about that antisocial behavior and why it is problematic. The third level is application. Once the juvenile understands the problematic behavior, opportunities for him or her to learn and practice appropriate behavior become the focus of rehabilitation and education. Demonstration is the final level of the Rehabilitation and Education phase. In this level, the expectation is that the juvenile will demonstrate the application of adaptive behavior in new contexts and situations within the facility. Juveniles move from one level to the next based on achieving behavioral and treatment goals communicated to them via regularly scheduled bimonthly consultations with the juvenile's treatment team. The treatment team generally includes the juvenile's counselor, a security guard, and an education representative. Juveniles who do not meet behavioral goals can be retained at each level until the specific behavioral or treatment requirements are met. If behavioral expectations worsen, juveniles can be demoted to a lower level.

In the state of Indiana, the Transition phase involves two steps. The first step of transition is referred to as Transition Administrative Release Committee (ARC). Transition ARC refers to the phase when a juvenile has maintained behavioral criteria at Level 4 and meets the behavioral and treatment requirements established at intake and mandated by the courts which sent the juvenile to confinement. Like every other level of rehabilitation, remaining in the Transition ARC phase is contingent upon the juvenile's behavior. For example, if a juvenile was at the Transition ARC level and he or she engaged in a behavioral or treatment violation, the treatment team could decide to retain him or her longer at the Transition ARC level or demote the juvenile to a previous level, thus extending the juvenile's stay and postponing release. The second step of the Transition phase is Release ARC. Release ARC includes a final team meeting with the juvenile to sign release papers and make final arrangements for the return to his or her home placement and community. The length of the Release ARC is brief, usually a few days in length. As with the Transition ARC phase, the juvenile's exit can be prolonged if 
a behavioral violation occurs. The total length of stay for girls on average is between four and six months. The total length of stay for boys is slightly longer, approximately five to eight months.

The first author of this article has conducted research and has worked directly with staff and juveniles in the correctional facilities. A doctoral dissertation examining the process of transition from correctional confinement using best practice principles, derived from a comprehensive literature review, showed that the state of Indiana faces the same barriers to community reentry when juveniles transition from correctional confinement (Spegel, 2016). Ochoa, Levy, Spegel, and Ovares (2015) and Ochoa (2016) also note that many of the academic and behavioral gains made by juvenile offenders during the time of correctional confinement are lost upon return to the community.

\section{Barriers to Community Reentry}

Limited vocational support and lack of sustained community reentry are two barriers to community reintegration. Many juvenile offenders have poor vocational attainment and lack work experience. Because correctional institutions tend to have limited resources, many juvenile offenders are denied the opportunity to attend vocational and training programs while under the supervision of the juvenile justice system (Steinberg, Chung, \& Little, 2004). These deficits directly affect exoffenders' ability to gain and maintain employment (Abrams \& Snyder, 2010; Petersilia, 2003; Visher, Winterfield, \& Coggeshall, 2005). The risk of remaining unemployed for long periods of time appears to be even more problematic among juvenile offenders compared to adult offenders (Osgood, Foster, Flanagan, \& Ruth, 2005). Chung, Little, Steinberg, and Altschuler (2005) found that delinquent juveniles were seven times more likely than their nondelinquent peers to be unemployed during adulthood.
The most neglected aspect of education support for juveniles involved with the criminal justice system is when the juvenile offender returns to the community (Clark et al., 2011). According to Osher, Amos, and Gonsoulin (2012), transition is a bidirectional coordinated set of activities that facilitates the successful movement of a juvenile offender from the community to a correctional facility, and from confinement back to the community. Successful reintegration into a community is marked by socially and legally appropriate behavior, and by avoiding any further contact with the criminal justice system. The process of reintegrating students from juvenile correctional facilities to their home communities poses challenges (Nellis \& Wayman, 2009). One obstacle to transition is that the juveniles often return to the same social and economic conditions that led to their incarceration. Additionally, juvenile offenders leave facilities with limited life skills, support to return to school, or support to find and maintain employment. Put simply, there is poor access to and inefficient coordination of transition services once students leave confinement (Ochoa et al., 2015). Informed by a comprehensive review of the literature on transition and research conducted by Ochoa, the authors of this article designed a program in which undergraduate students provide mentoring support to incarcerated juveniles.

\section{Empirical Support for Mentoring}

Mentoring is one of the oldest forms of community-based interventions for youth, the concept for which is attributed to Homer's The Odyssey, and has formally existed in the U.S. since the early 1900s (Colley, 2000). DuBois and colleagues (2011) reported that as of 2011, there were over 5,000 mentoring programs in the U.S., reaching an estimated 3 million American youth. The Office of Juvenile Justice and Delinquency Prevention appropriated $\$ 769$ million for mentoring since 2008 (OJJDP, 2016). The benefits of mentoring are extolled by educators and policymakers alike. 
The Big Brothers Big Sisters of America (2016) program, one of the most well-researched mentoring programs, has been credited for decreasing incidents of violence, drug use, and school absences among participants 18 months after mentoring. Research on other mentoring programs has produced empirical evidence which confirms that mentoring can have significant, positive impacts on youth who are in need of emotional and instrumental support, which refers to more tangible assistance such as helping a juvenile obtain a bus pass to get to an interview or providing a practice book to prepare for the General Education Degree (GED) examination. Jones, Clark, and Quiros (2012) assert that one of the most important roles of mentors is to help youth improve goal-setting skills and inspire hope for the future. In addition, mentors are important in helping mobilize existing resources for mentees as they work toward their goals, helping connect them to community resources and keeping them engaged (Lerner, 2005).

A review of literature on mentoring programs conducted by Matz (2014) showed mentoring juveniles when they return to their home community after correctional confinement had positive effects and reduced the risk of recidivism. Similarly, in 2016, the Center for Promise published a report in which they interviewed 120 high school dropouts who eventually returned to get their diploma about the catalysts for them deciding to drop out and later deciding to resume their education. The results from the report found that positive relationships helped mentees face challenging life events. When questioned about why they dropped out of school, students reported it was often due to a lack of support particularly in regards to academic achievement. Conversely, when the same students were asked about the reason they decided to return to school, the students often attributed the decision to return to school to a mentor or person who encouraged them or helped them overcome the barriers to graduation. Importantly, these outside supports were most effective when they provided a combination of consistent and stable emotional and instrumental support. The report indicated that many of the youth studied lacked these critical relationships in their natural networks. The researchers asserted that formal mentors can fill that gap, encouraging and developing their mentee while helping connect them to other community resources that can help them succeed academically and vocationally. The Center for Promise report followed decades of research in child development that emphasized the importance of healthy relationships during childhood and adolescence (Benson, Scales, Hamilton, \& Semsa, 2006; Theokas \& Lerner, 2006).

Gaps in resources, opportunities, and positive relationships can be particularly large for incarcerated juveniles and even more so for juveniles with disabilities, who often need more and have fewer supports than other peers (Clark et al., 2011). Students facing an "opportunity gap" are $81 \%$ more likely to participate in extracurricular activities if they are being mentored (Bruce \& Bridgeland, 2014). In another study of youth in correctional facilities, one group of juveniles was provided enhanced transition services as they left juvenile confinement and returned to their communities (Clark et al., 2011). They were $64 \%$ less likely to recidivate within a month than those without enhanced services. The enhanced transition services included academic and vocational assessments; creating résumés; and obtaining copies of vital records, transcripts, credit analyses, certificates or diplomas, and samples of work, in addition to the basic services all students in facilities received. Enhanced services were provided by transition coordinators in the study who were formally employed by the correctional facilities but whose work resembled the work of a mentor (Clark et al., 2011).

\section{The HOPE Mentoring Program}

The HOPE Mentoring Program is designed to provide employment-related support to juveniles in residential correctional confinement. 
Employability skills are emphasized because research shows that employment is a protective factor against crime and recidivism (Graffam, Shinkfield, Lavelle, \& McPherson, 2004). The HOPE Mentoring Program is university-based, meaning that undergraduate students are recruited to serve as HOPE mentors from a variety of academic majors. The first step to becoming a HOPE mentor is to clear a background screening requirement set forth by the Indiana Department of Correction. The second step is to complete five online training modules created specifically for the HOPE Mentoring Program. The training modules cover topics such as developmental characteristics of incarcerated juveniles, the role of a mentor, policies and procedures on mandatory child protective services reporting, and expectations for HOPE mentors. In addition, suggestions are provided to help HOPE mentors develop relationships with mentee participants. After completing the five training modules, each volunteer is required to visit an Indiana juvenile correctional facility to familiarize themselves with their operations and introduce themselves to facility staff and students.

\section{Principles of the HOPE Mentoring Program}

Once trained, mentors are matched to a mentee and the mentoring relationship begins. There are three principles that guide the delivery of HOPE mentoring. Each principle is described below:

1. Exit Begins at Entry - Risler and $\mathrm{O}^{\prime}$ Rourke (2009) recommended that preparation to reenter the community after correctional confinement should begin from the moment the juvenile enters the facility. Correctional personnel in Indiana are aware of the importance of planning for community reentry in the early stages of incarceration. However, in reality, the fact that there is only one or two transition coordinators per facility proves challenging. As such, the transition process is often rushed and is less thorough than best practice recommends. In response to this obstacle, the HOPE Mentoring Program pairs mentors with juveniles during the intake process. Starting mentoring during the initial phase of correctional confinement helps build a stronger relationship between the mentor and mentee and increases the probability of sustaining the relationship when a juvenile exits confinement. In addition, because the mentor is connected to the mentee during the entire phase of correctional confinement, the mentor also serves to support the facility transition coordinator by providing individualized support to the mentee under his or her direction. In a sense, the mentor serves as a bridge between the facility and the community by providing continuity of services from incarceration to release when the juvenile reenters his or her community. HOPE mentors meet with the correctional facility transition coordinator and the juvenile during the time of confinement to plan for the activities that will take place after discharge (e.g., confirming the address where the mentee is going to be released, contacting the school where the student will be re-enrolling to make sure records are sent, and sending job applications). Once the juvenile is released, mentors continue to meet with the juvenile on a weekly basis face-to-face and may have daily contact via text messaging, phone calls, or e-mails.

2. Collaboration with Facility Staff and Community Organizations - The HOPE Mentoring Program is not a stand-alone university program. Collaboration is an essential component of the program. Each juvenile in confinement interacts with security and treatment personnel within the living unit and education personnel within the school. However, communication between facility personnel is not always optimal, making collaboration between different service providers a challenge. Because the HOPE mentor is assigned only to one juvenile, that HOPE mentor functions as a conduit for 
communication and collaboration. As previously mentioned, HOPE mentors assist the transition coordinator in the facility to accomplish the goals set for each juvenile in their ILP or IEP. The HOPE Mentoring Program is embedded in the programs that already exist in the facility, and mentors help each student work toward academic, treatment, or employment goals set by the juvenile and facility staff. As such, mentors work as liaisons between security, treatment, and school personnel when the juvenile is in confinement and between the facility, parents, and community school when the juveniles exit correctional confinement. For example, a mentor might assist the transition coordinator in communicating with the juvenile's counselor about an upcoming meeting that would otherwise be forgotten. In the community, the mentor might help school staff secure the appropriate transcript records for a juvenile when he or she re-enrolls at a community school after release from confinement. The more the HOPE Mentoring Program is embedded as part of the education and rehabilitation program, the better resource brokers mentors can be for their mentees. Mentors can also help explore and provide information about which businesses might hire juveniles, where students can find academic support, which organizations already exist to serve youth seeking employment, and who else in the community is willing to support a mentee as they exit correctional facilities. This information can only be obtained through collaboration with community organizations brokered by the HOPE mentors.

3. Positive and Responsive Mentoring-The HOPE Mentoring Program strives to create an environment of hopefulness and positivity, which inspires and encourages mentees toward the goals that have been set. The needs and interests of juveniles with disabilities are taken into account within this principle. For example, if the juvenile has a specific reading disability, the mentor designs activities that are at the appropriate reading level or reads anything the juvenile is unable to read from a job application. Another approach when the juvenile has a disability is to work alongside the special education coordinator who is trained in special education and can guide the mentor as he or she works with the juvenile mentee. Nellis and Wayman (2009) describe the role of mentors as being positive adults who encourage and support juveniles. Most incarcerated juveniles feel like they are surrounded by adults with whom they continue to have negative interactions. At home, parents punish them for acting out. At school, teachers give them office referrals, detentions, and suspensions for misbehavior. In the community, law enforcement agents arrest them, and judges send them to juvenile detention for misbehavior. Once in confinement, correction personnel enforce strict rules from the moment a juvenile arrives to the time of release. By design, the HOPE Mentoring Program does not insist on juveniles accomplishing anything. HOPE mentors show up with activities for each session, but if the juvenile is unwilling or unable to do them, the mentor shifts to another activity. In some cases, the HOPE mentor simply shows up. A HOPE mentor rewards any adaptive behavior of the juvenile mentees and remains positive, consistent, patient, and respectful regardless of the juvenile's behavior. Counterintuitive as it may sound, the non-insistence of HOPE mentors for mentees to accomplish any task during the weekly session diminishes the likelihood that juveniles are going to rebel against a mentor by refusing to do a task. The mentor relationship is itself the curative and healing experience. Participation in this program is voluntary at every level.

Helping mentees learn to set goals is one of the most important tasks of a mentor (Jones et al., 2012). Clinkinbeard and Zohra (2011) noted that mentors could help mentees enhance their self-esteem and develop positive emotions. They also 
noted that mentors could help mentees understand the behaviors that prevent juveniles from realizing the goals they set for themselves. In short, goal setting can provide much needed motivation and is thus an important part of mentoring a juvenile. In addition to positivity, the HOPE Mentoring Program uses a responsive approach which means that HOPE mentors individualize the activities and their mentoring style to fit each juvenile mentee. For example, mentoring activities for older juveniles might focus on earning their GEDs or practicing for a job interview, while younger juveniles who may be years from being old enough to work might only explore different career options. Mentors are also responsive to behavior, committing to mentoring whether the mentee is in a good mood or otherwise. If a mentee refuses to participate in any of the planned activities in a session, the HOPE mentor will happily sit with the mentee until the session is over, and will happily return the next week. Mentors may have open conversations about a mentee's negative behaviors but remain positive, attempting only to understand the nature of the juvenile's disinterest. As such, HOPE mentors are trained to help juveniles in setting goals, both pertaining to their transition out of the correctional facility and to long-term education and employment.

\section{Conclusion}

While federal legislature requires juvenile correctional facilities to provide education and transition services for all juveniles who serve a sentence, each state and facility independently determines how these services are executed. A variety of barriers exist for staff and juveniles that often result in many youth leaving a facility without transition support, returning to their unchanged communities with little means to maintain any gains they may have made during their sentence. The
HOPE Mentoring Program uses undergraduate students from college and university campuses across Indiana to help bridge this resource gap both while the juveniles are in confinement and when they are released to their communities. By design, the HOPE Mentoring Program is guided by three main principles: (1) exit begins at entry, (2) collaboration with facility staff and community organizations, and (3) positive and responsive mentoring. These principles help address the need to begin transition planning during intake, improve communication between the many parties involved in the juveniles' correction experiences and reintegration into their communities, and increase the juveniles' desire to participate in the program and work toward their own academic and vocational goals. Ultimately, participation in the HOPE Mentoring Program may decrease the likelihood of a juvenile recidivating and increase the chances that they will have academic and vocational success upon release from a correctional facility.

\section{References}

Abrams, L. S., \& Snyder, S. M. (2010). Youth offender reentry: Models for intervention and directionsforfutureinquiry. Children and Youth Services Review, 32(12), 1787-1795. https:// doi.org/10.1016/j.childyouth.2010.07.023

Anthony, E. K., Samples, M. D., de Kervor, D. N., Ituarte, S., Lee, C., \& Austin, M. J. (2010). Coming back home: The reintegration of formerly incarcerated youth with service implications. Children and Youth Services Review, 32(10), 1271-1277. Retrieved from www.sciencedirect.com/science/article/ pii/S0190740910001271

Baltodano, H. M., Platt, D., \& Roberts, C. W. (2005). Transition from secure care to the community: Significant issues for youth in detention. Journal of Correctional Education, 56(4), 372-388. Retrieved from www.jstor. org/stable/23282627 
Benson, P. L., Scales, P. C., Hamilton, S. F., \& Semsa, A., Jr. (2006). Positive youth development: Theory, research, and applications. In R. M. Lerner (Ed.), Handbook of child psychology: Vol. 1. Theoretical models of human development (6th ed., pp. 894-941). Hoboken, NJ: Wiley.

Big Brothers Big Sisters of America. (2016). The Big Brothers Big Sisters match. Retrieved from www.bbbs.org/impact

Bruce, M., \& Bridgeland, J. (2014). The mentoring effect: Young people's perspectives on the outcomes and availability of mentoring. Washington, DC: Civic Enterprises with Hart Research Associates for MENTOR: The National Mentoring Partnership. Retrieved from www.civicenterprises.net/Education

Center for Promise. (2016). Don't quit on me: What young people say about the power of relationships. Washington, DC: America's Promise Alliance.

Chung, H. L., Little, M., Steinberg, L., \& Altschuler, D. (2005). Juvenile justice and the transition to adulthood. Network on Transitions to Adulthood Policy Brief, Issue 20.

Clark, H. G., Mathur, S. R., \& Helding, B. (2011). Transition services for juvenile detainees with disabilities: Findings on recidivism. Education and Treatment of Children, 34(4), 511529. https:// doi.org/10.1353/etc.2011.0040

Clark, H. G., \& Unruh, D. (2010). Transition practices for adjudicated youth with E/BDs and related disabilities. Behavioral Disorders, $36(1)$, 43-51. Retrieved from http://amy wagner.wiki.westga.edu/file/view / transitions+adjudactaed.pdf

Clinkinbeard, S. S., \& Zohra, T. (2012). Expectations, fears, and strategies: Juvenile offender thoughts on a future outside of incarceration. Youth $\mathcal{E}$ Society, 44(2), 236-257. Retrieved from http://yas.sagepub.com. proxyiub.uits.iu.edu/content/44/2/236. short

Colley, H. (2002). A "rough guide" to the history of mentoring from a Marxist feminist perspective. Journal of Education for Teaching, 28(3), 257-273.

Davis, L. M., Steele, J. L., Bozick, R., Williams, M., Turner, S., Miles, J. N. V., \& Steinberg, P. S. (2014). How effective is correctional education, and where do we go from here? The results of a comprehensive evaluation. Retrieved from www.rand. org/pubs/research_reports/RR564.html

Dubois, D. L., Portillo, N., Rhodes, J. E., Silverthorn, N., \& Valentine, J. C. (2011). How effective are mentoring programs for youth? A systematic assessment of the evidence. Association for Psychological Science, 12(2), 57-91. https://doi.org/10.1177/15291006114 14806

Graffam, J., Shinkfield, A., Lavelle, B., \& McPherson, W. (2004). Variables affecting successful reintegration as perceived by offenders and professionals. Journal of Offender Rehabilitation, 40(1/2), 147-171.

Jekielek, S., Moore, K. A., \& Hair, E. (2002). Mentoring programs and youth development: A synthesis. Retrieved from https:// www.childtrends.org/wp-content/ uploads/2002/08/mentorrpt.pdf

Jones, M. A., Clark, P. A., \& Quiros, R. J. (2012). Juvenile corrections and mentoring: The referral stage. Washington, DC: Office of Juvenile Justice and Delinquency Prevention.

Lerner, R. M. (2005). Promoting positive youth development: Theoretical and empirical bases (White paper prepared for the Workshop on the Science of Adolescent Health and Development, National Research Council/ Institute of Medicine). Washington, DC: National Academies of Science. 
Matz, A. K. (2014). Do youth mentoring programs work? A review of the empirical literature. OJJDP Journal of Juvenile Justice, 3(2), 83-101.

Nellis, A., \& Wayman, R. H. (2009). Back on track: Theory, research, and promising approaches for youth reentry. Washington, DC: Youth Reentry Taskforce of the Juvenile Justice and Delinquency Prevention Coalition.

Ochoa, T. (2016). Improving transition support to juvenile offenders with disabilities through a collaborative approach. Intervention in School and Clinic, 52(1), 1-7.

Ochoa, T., Levy, L. J., Spegel, K. M., \& Ovares, Y. F. (2015). Keeping kids out of corrections: Lowering recidivism by strengthening teamwork and collaboration between law enforcement officers and transition coordinators in juvenile correctional facilities. Law Enforcement Executive Forum, 15(1), 29-43.

Office of Juvenile Justice and Delinquency Prevention (OJJDP). (2016). OJJDP's investment in mentoring. Retrieved from www. nationalmentoringresourcecenter.org/index. php/ojjdp-mentoring/ojjdp-s-investment-inmentoring.html

Osgood, W., Foster, E. M., Flanagan, C., \& Ruth, G. R. (Eds.). (2005). On your own without a net: The transition to adulthood for vulnerable populations. Chicago: University of Chicago Press.

Osher, D., Amos, L. B., \& Gonsoulin, S. (2012). Successfully transitioning youth who are delinquent between institutions and alternative and community schools. Washington, DC: American Institutes for Research. Retrieved from www. neglected-delinquent.org/sites/default/ files/docs/successfully_transitioning_youth. pdf

Petersilia, J. (2003). When prisoners come home: Parole and prisoner reentry. New York: Oxford University Press.
Risler, E., \& O’Rourke, T. (2009). Thinking exit at entry: Exploring outcomes of Georgia's juvenile justice educational programs. Journal of Correctional Education, 60(3), 225-239.

Sheldon-Sherman, J. (2010). No incarcerated youth left behind: Promoting successful school reentry through best practices and reform. Children's Legal Rights Journal, 30(2), 22-37.

Spegel, K. M. (2016). A case study of adolescent girls transitioning from juvenile correctional facilities into community schools (Order No. 10196179). Available from Dissertations \& Theses @ CIC Institutions; ProQuest Dissertations \& Theses Global (1848961130). Retrieved from http://ezproxy.lib.indiana.edu/login? url=http: / / search.proquest.com / docview $/ 1848961130$ ?accountid=11620

Steinberg, L., Chung, H. L., \& Little, M. (2004). Reentry of young offenders from the justice system: A developmental perspective. Youth Violence and Juvenile Justice, 2(1). Retrieved from http://journals.sagepub.com/doi/ abs/10.1177/1541204003260045

Stephens, R. D., \& Arnette, J. L. (2000). From the courthouse to the schoolhouse: Making successful transitions. Washington, DC: U.S. Department of Justice, Office of Justice Programs, Office of Juvenile Justice and Delinquency Prevention. Retrieved from www.ncjrs.gov/pdffiles1/ ojjdp/178900.pdf

Suitts, S., Dunn, K., \& Sabree, N. (2014). The imperative to transform juvenile justice systems into effective educational systems: A study of juvenile justice schools in the south and the nation. Atlanta, GA: Southern Education Foundation. Retrieved from www. southerneducation.org/cmspages/getfile.aspx?guid=b80f7aad-405d-4eed-a9668d7a4a12f5be

Theokas, C., \& Lerner, R. M. (2006). Promoting positive development in adolescence: The role of ecological assets in families, schools, 
and neighborhoods. Applied Developmental Science, 10(2), 61-74.

U.S. Departments of Education and Justice. (2014). Guiding principles for providing highquality education in juvenile justice secure care settings. Washington, DC: U.S. Departments of Education and Justice. Retrieved from https://www2.ed.gov/policy/gen/guid/ correctional-education/guiding-principles. pdf

Visher, C. A., Winterfield, L., \& Coggeshall, M. B. (2005). Ex-offender employment programs and recidivism: A meta-analysis. Journal of Experimental Criminology, 1(3), 295316. https://doi.org/10.1007/s11292-005-81 $27-x$

Theresa A. Ochoa is an associate professor interested in the school-to-prison pipeline. She is the founder and Executive Director of HOPE.

Sarah D. Swank is Indiana's statewide juvenile mentoring director and served as an undergraduate co-founder of HOPE. 
Copyright of Law Enforcement Executive Forum is the property of Law Enforcement Executive Forum and its content may not be copied or emailed to multiple sites or posted to a listserv without the copyright holder's express written permission. However, users may print, download, or email articles for individual use. 